\title{
Challenging home abortion in Scotland: Society for the Protection of Unborn Children v Scottish Ministers [2018] CSOH 85
}

\author{
Robert Brett Taylor and Adelyn L. M. Wilson
}

\section{A. INTRODUCTION}

Abortions are potentially illegal under Scots common law unless they meet the criteria set down in the Abortion Act 1967: namely that they are performed by a registered medical practitioner on specific medical grounds, and in an approved location. Section 1(3) of the Act lists various types of hospital as approved locations and authorises Ministers to approve individual locations on a case-by-case basis. Section 1(3A), inserted by the Human Fertilisation and Embryology Act 1990, allows Ministers to approve a "class of places".

On 26 October 2017, exercising their section 1(3A) powers, the Scottish Ministers approved "[t]he home of a pregnant woman who is undergoing treatment for the purposes of termination of her pregnancy". The home was interpreted as "the place in Scotland where a pregnant woman is ordinarily resident". ${ }^{2}$ So-called medical or pharmaceutical abortion is achieved through taking, first, the feticide mifepristone and, a day or so later, misoprostol to evacuate the pregnancy. The Approval allowed the taking of misoprostol at home where: the woman has been prescribed both medications at a clinic, has taken mifepristone there, and has expressed desire to take misoprostol at home. ${ }^{3}$

The Approval is unpublished by the Scottish Government. It was circulated to health boards and like institutions by the Government's Chief Medical Officer along with Guidance for the Approval's implementation which had been prepared by the Scottish Abortion Care Providers Network. ${ }^{4}$ That Guidance comprised "inclusion criteria" for consideration by doctors when deciding whether to allow home abortion, a list of medical conditions which would prevent home abortion, and a detailed procedural check list for the doctor to follow in home abortion cases.

The Society for the Protection of Unborn Children (SPUC) challenged the lawfulness of this Approval by a judicial review action, which was heard in the Court of Session's Outer House by Lady Wise in May 2018. She rendered judgment on 15 August 2018 in favour of the Scottish Ministers. ${ }^{5}$ The importance of her decision extends beyond Scotland: England will implement home abortion on the Scottish model following the decision; ${ }^{6}$ Wales has already done so. ${ }^{7}$ The SPUC has appealed and the case has progressed to the Inner House. ${ }^{8}$

\footnotetext{
${ }^{1}$ Abortion Act 1967 (Place for Treatment for the Termination of Pregnancy) (Approval) (Scotland) 2017, para 3.

2 Ibid para 2.

3 Ibid para 4.

${ }^{4}$ Scottish Abortion Care Providers Network, "Early Medical Abortion at home up to 9 weeks +6 Days gestation (EMAH): Guidelines for early medical abortion with self-administration of misoprostol in the home setting", available at https://www.sehd.scot.nhs.uk/cmo/CMO(2017)14.pdf.

${ }^{5}$ Society for the Protection of Unborn Children v Scottish Ministers [2018] CSOH 85.

${ }^{6}$ Department of Health and Social Care, "Government confirms plans to approve the home-use of early abortion pills", available at https://www.gov.uk/government/news/government-confirms-plans-to-approve-the-homeuse-of-early-abortion-pills.

${ }^{7}$ Abortion Act 1967 (Approval of Place for Treatment for the Termination of Pregnancy) (Wales) 2018.

${ }^{8}$ Court of Session Rolls, 12 September, Extra Division of the Inner House.
} 
This article analyses the judgment at first instance and submits that its rationale is unsound; this raises questions for the UK-wide adoption of the Scottish model. This article also addresses outstanding questions about the Approval and Guidance. Significant issues with the legality of the Approval on public law grounds are explored by the authors elsewhere. ${ }^{9}$

\section{B. THE DECISION}

There were two points at issue. First, whether a home is a permissible class of places for the purposes of the 1967 Act. Secondly, whether the treatment anticipated in the Approval is performed by a registered medical practitioner as required by section $1(1)$. However, these issues are blurred thus resulting in overlap between the corresponding parts of the judgment. Moreover, the Scottish Government's failure to support all of its arguments resulted in Lady Wise's reasoning becoming somewhat remote from the parties' legal argumentation in places. ${ }^{10}$

Both parties accepted that pregnant women can currently self-administer misoprostol at an approved place then immediately leave so that the loss of pregnancy occurs at home. ${ }^{11}$ Lady Wise also explicitly "proceed[ed] on the basis that no issue is taken with the [treatment process] as a safe method to terminate pregnancy". ${ }^{12}$

\section{(1) Pregnant women's homes as a "class of places"}

The petitioners disputed the lawfulness of pregnant women's homes as a "class of places" for the purposes of section $1(3 \mathrm{~A})$, making three interconnected arguments.

First, that a competent class of places cannot be so broad as to comprise all homes of pregnant women undertaking abortion treatment. Places within a class must also be linked by shared features unconnected to a user (i.e. the woman). ${ }^{13}$ Lady Wise determined that the class is "a real and substantive restriction on location" because the woman is restricted in that she cannot take the medication anywhere other than her home. ${ }^{14}$ Furthermore, "there is at least a rational basis for identifying the place of ordinary residence" because the doctor must know the location where the patient will continue the course of treatment. ${ }^{15}$

Secondly, applying the reasoning of Lords Diplock and Keith that Parliament's intention in 1967 was to provide for "safe and hygienic" abortion conditions, ${ }^{16}$ that the Approval must fail because all pregnant women's homes are not necessarily safe and hygienic. While conceding that safety was a relevant consideration, the Government suggested that the test was a broader one of "suitability",

\footnotetext{
${ }^{9} \mathrm{R}$ B Taylor and A L M Wilson, “Approving home abortion in the UK: Executive decisions, delegated legislation and the rule of law" (forthcoming).

${ }^{10}$ See R B Taylor and A L M Wilson, "Outer House arguments over lawfulness of abortion treatment at home", Scottish Legal News (18 May 2018) available at www.scottishlegal.com/article/judicially-reviewing-thelawfulness-of-abortion-treatment-at-home-summary-of-arguments-in-the-outer-house.

11 SPUC para 34.

12 Ibid para 29.

13 Ibid para 12.

${ }^{14}$ Ibid para 31.

15 Ibid.

${ }^{16}$ Ibid para 9; Royal College of Nursing of the United Kingdom $v$ the Department of Health and Social Security [1981] AC 800.
} 
also comprising issues such as privacy. ${ }^{17}$ The Government appears to have drawn this wording from the report of Standing Committee F during the passage of the 1967 Act. ${ }^{18}$

Lady Wise confirmed that the appropriate test was one of suitability rather than purely safety, although she used the terms interchangeably. ${ }^{19}$ It was unnecessary to show that all pregnant women's homes would be suitable, because this would "underplay that the woman's wish to take the misoprostol at home is an important restriction contained within the approval." ${ }^{20}$ It can "be readily inferred" that suitability would be considered by the pregnant woman when deciding whether to request a home abortion. ${ }^{21}$

The petitioner further argued that, because not all homes are safe or suitable, the Government was in effect delegating its power to identify and approve places to doctors on a case-by-case basis. Lady Wise disputed this, stating that "the approval does not delegate to the medical profession the decision on suitability of the home as a class of place." 22 However, the situation is arguably worse than the petitioners claimed. Despite suggesting that the doctor has the final medical decision, the corollary of the above is that the principal burden of assessing a place's suitability now rests on the patient. Suitability accordingly becomes a subjective test by the patient rather than an objective one by the doctor.

Several further issues arise, beyond those contemplated in court. First, judicial delegation of the suitability test to the patient may create a de facto right for the patient to make that determination. Such a situation goes beyond the Approval's wording, which seems to use the woman's desire for home abortion to prevent her from being compelled to take the medication at home rather than in a clinic setting, not to give her discretion to make a substantive contribution to the assessment of the location's suitability. This is inconsistent with the 1967 Act, which puts the full evaluative burden on the doctor and is widely criticised for limiting patient autonomy thereby. ${ }^{23}$ Secondly, the patient has no framework of reference on which to make a substantive judgment as to suitability because she has no practical recourse to the Approval or the Guidance. Thirdly, the Guidance does not direct the doctor accurately. The Guidance requires the doctor to determine that there is "[n]o cause for concern regarding wellbeing at home", ${ }^{24}$ which falls far short of an assessment of suitability.

Thirdly, through these two interconnected arguments, the petitioners made the wider point that the executive's power to approve a "class of places" was restricted. However, despite stating that the place must be suitable, Lady Wise held that:

[T]here is nothing in the legislation that restricts the classes of place that can be approved to those in a similar category to hospitals or clinics. The power to approve a class of place is given

\footnotetext{
17 SPUC para 19.

18 Ibid para 17; Parliamentary Debates: House of Commons Official Report: Standing Committee F: Medical Termination of Pregnancy Bill, 18 January to 5 April 1967 (London: HMSO 1967).

${ }^{19}$ SPUC para 32.

20 Ibid para 33.

$21 \mathrm{lbid}$.

22 lbid.

${ }^{23}$ See e.g. S Sheldon, "The decriminalisation of abortion: An argument for modernisation" (2016) 36 Oxford Journal of Legal Studies 334-365; E Jackson, "Abortion, autonomy and prenatal diagnosis" (2000) 9 Social and Legal Studies 467-494.

${ }^{24}$ Scottish Abortion Care Providers Network, "Early Medical Abortion at home", i.
} 
without limitation as to specific features, subject always to the respondents requiring to meet the administrative law tenets of reasonableness and rationality. ${ }^{25}$

This shows considerable deference to the Government's argument. ${ }^{26}$ However, the exercise of any decision-making powers must be restricted by the purpose of the enabling Act.. It is therefore unfortunate that both parties excluded reference to Hansard with respect to the parliamentary intention of both the 1967 and 1990 Acts. This was a significant mistake by the petitioner. As we have shown elsewhere, there was detailed parliamentary discussion of whether the section 1(3A) powers delegated by the 1990 Act would or could be used to allow home abortions and the then Secretary of State for Health, Kenneth Clarke, gave assurances in the negative. ${ }^{27}$

Lady Wise concluded her discussion of this submission by introducing a new test, which the petitioners failed to satisfy:

it would be necessary to explain or offer to prove why an outpatient clinic or GP's premises would necessarily be a safer place to take a tablet or pessary as the second stage of a pregnancy termination treatment than the woman's home[.] $]^{28}$

This test is problematic: it lacks clarity, its relationship to that of suitability is unclear, and it reveals the difficulty caused by the scant discussion of the medical process during proceedings. Lady Wise's examples are also self-defeating: neither outpatient clinics nor GP's surgeries are approved classes of place under section 1(3) and therefore could only be used for abortion treatment legally where they had been assessed and approved as a specific licensed premise by the Executive under section 1(3). It would be interesting to see whether a future appeal or challenge would address this test.

\section{(2) Treatment by a registered medical practitioner}

The petitioners argued that self-administering misoprostol at home without direct medical supervision is inconsistent with treatment by a registered medical practitioner, as required by section 1(1) of the 1967 Act.

Lady Wise held, with respect to wider medical practice, that "patients who self-administer medication at home may still be described as being treated by their medical practitioner" even if outwith their direct supervision, as in cases of diabetes. ${ }^{29}$ This comparison is questionable, as there was little contemplation in the proceedings of the complexities of self-administration of the abortion medication. For example, misoprostol tablets can be taken orally during the first seven weeks of pregnancy. Thereafter multiple tablets are required to dissolve in the cheek or under the tongue for 30 minutes, or be inserted vaginally (which is the traditional method, according to the Guidance), and may require repeat doses. ${ }^{30}$

Because the patient can already self-administer misoprostol in the clinic setting, Lady Wise stated that "the extension of the place at which that self-administration can be carried out, from a clinic to home, does not offend the requirement that treatment be carried out by a registered medical practitioner". ${ }^{31}$

\footnotetext{
${ }^{25}$ SPUC para 33.

${ }^{26}$ Ibid para 20.

27 Taylor \& Wilson (fn 9).

28 SPUC para 43.

${ }^{29}$ Ibid para 40.

30 National Institute for Health and Care Excellence, "British National Formulary: Misoprostol", available at https://bnf.nice.org.uk/drug/misoprostol.html.

${ }^{31}$ Ibid.
} 
She justifies this on the basis that the House of Lords in Royal College of Nursing had adopted a purposive approach to interpretation of the 1967 Act in light of intervening medical advancements and, likewise, that "[t]he nature of that control [by the doctor] has necessarily evolved as the treatment for the termination of pregnancy has developed." ${ }^{32}$ However, this justification is problematic. That earlier case arose because a distinct treatment process had emerged which had not been contemplated in 1967. The purposive approach allowed the new treatment to be adopted in a practical manner. However, the same justification for judicial reinterpretation does not apply in the present circumstances. Section 1(3A) was introduced in 1990 in direct contemplation of medical abortion by pharmaceutical intervention becoming available. The nature of the treatment under current discussion remains the same. This was even conceded by the Government in their submissions. ${ }^{33}$

Some of Lady Wise's conclusions might have implications for wider health care practice. In Royal College of Nursing, the House of Lords acknowledged that abortion requires a treatment team. Lady Wise extends the concept of the treatment team to include the patient: in taking the tablet at the doctor's instruction, "the pregnant woman herself requires to be an active participant in [the team]." ${ }^{34}$ The doctor need only know the woman's location while self-administering (namely her home) to remain in control. ${ }^{35}$ In the abortion context, this role, coupled with her role in the suitability test, gives the patient a greater burden of responsibility and control over determinative factors within her treatment. This constitutes a significant shift from the situation contemplated by the 1967 Act, and misinterprets the concept of patient autonomy. Further, if extended to other treatments, as suggested by Lady Wise's comparative examples mentioned above, this is a change in healthcare law which may affect some of the medical team's traditional civil liability and reduce patients' recourse against the other team members.

Finally, Lady Wise construes section 1(1) of the 1967 Act "as permitting the second stage of pharmaceutical termination to take place in the pregnant woman's home (where she so wants) with self-administration of misoprostol." ${ }^{36}$ This is significant because Lady Wise implies that a purposive reinterpretation of the 1967 Act would allow home abortion irrespective of any Approval.

\section{(3) Additional problems arising from the points made}

The case can further be criticised for failing fully to explore certain key issues.

First, the parties and Lady Wise accepted that the Approval was an instrument recording an executive decision rather than delegated legislation. ${ }^{37}$ Lady Wise also concluded, going further than the parties' statutory construction, that the Scottish Ministers had received their section 1(3A) powers in the Scotland Act $1998 .{ }^{38}$ We have shown elsewhere that both of these conclusions are incorrect. The Approval can only be understood as delegated legislation and section $1(3 \mathrm{~A})$ as a Henry VIII clause. Moreover, section 1(3A) was explicitly not conferred in the 1998 Act but rather only entered Scottish competence by default when the Scotland Act 2016 made abortion a devolved matter. ${ }^{39}$

\footnotetext{
32 Ibid para 40.

33 Ibid para 17.

${ }^{34}$ Ibid para 40.

${ }^{35}$ Ibid para 41.

${ }^{36}$ Ibid para 41.

${ }^{37}$ Ibid para 4.

${ }^{38}$ Ibid paras 16, 29.

39 Taylor \& Wilson (fn 9).
} 
Secondly, the parties and Lady Wise accepted that the Approval authorised self-administration. However, the Approval mentions only that the woman "wants to carry out the treatment at home". It neither explicitly allows self-administration nor excludes the need for medical supervision. A strict reading might suggest that medical personnel would need to attend the home at the point of administration of misoprostol. It is only the Guidance which, in interpreting the Approval, presumes self-administration.

Thirdly, Lady Wise expressed frustration that the Guidance was not brought within her contemplation. Indeed, the Guidance must be regarded as unlawful. It exceeds the Approval in several respects: the assumption of self-administration, introduction of a requirement that a second person be present in the home at the time of self-administration, and limitation of this treatment option to nine weeks and six days of gestation. Additionally, the Guidance does not direct the doctor to determine whether the patient wants to self-administer misoprostol at home, which is the test required in the Approval and the determining factor in Lady Wise's test for suitability, but only that the woman "wishes to pass the pregnancy at home". The petitioner's failure to bring this Guidance within judicial contemplation was thus undoubtedly an error, one that undermined their wider case. For example, Lady Wise had concerns as to whether a home was necessarily less suitable than a GP's office. Yet the petitioner, with reference to the Guidance, could have argued that the Chief Medical Officer's requirement that a second adult be present demonstrates that the situation contemplated by the Approval is unsafe. The Guidance could still be challenged in a separate action, perhaps brought by a woman who would be denied treatment under the Guidance but not under the Approval.

\section{CONCLUSION}

It is argued that this case was wrongly decided. Lady Wise demonstrates excessive deference to the Government's arguments and goes beyond the points raised.

More concerning still is the unconsidered suite of difficulties raised by the Approval and Guidance with respect to the criminal liability of those involved. A woman's failure to administer the medication at home (but, say, in another location) would put her beyond the protection from criminal prosecution offered by the 1967 Act as amended by the Approval. Given the inaccessibility of both the Approval and Guidance, the woman's sole recourse to this important information is through the doctor. The doctor is therefore in the position of advising the woman not just medically but also legally in relation to her criminal liability. Setting aside the fact that this advisory role is not made clear in the Guidance, this is beyond a doctor's professional capacity and dramatically reframes the doctor-patient relationship. It seems unlikely too that medical professional indemnity insurance would cover the situation where a doctor failed to give proper legal advice to a patient who was then held criminally liable for their implementation of a treatment programme. That there is no mention whatsoever of this issue in the Guidance suggests that patients are receiving no information on this, and risk unknowingly being made criminally liable. 